\title{
Sarcoidosis confined to the airway masquerading as asthma
}

\author{
George Mixides MD, Elizabeth Guy MD FCCP
}

G Mixides, E Guy. Sarcoidosis confined to the airway masquerading as asthma. Can Respir J 2003;10(2):114-116.

\begin{abstract}
A rare case of sarcoidosis is presented. A 32-year-old white woman initially diagnosed with asthma was to undergo thyroidectomy to eliminate what was thought to be the real source of her symptoms. Instead, the cause was found to be sarcoidosis involving only the major airways, without intrathoracic adenopathy, atelectasis, pulmonary parenchymal infiltrates or evidence of extra pulmonary disease. She rapidly responded to systemic glucocorticoids, which later was supplemented successfully by inhaled glucocorticoids for persistent cough.
\end{abstract}

Key Words: Asthma; Bronchoscopy; Glucocorticoids; Sarcoidosis

\section{Sarcoïdose confinée aux voies aériennes simulant un asthme}

RÉSUMÉ : Un cas rare de sarcoïdose est présenté. Une femme de race blanche âgée de 32 ans, ayant initialement reçu un diagnostic d'asthme, devait subir une thyroïdectomie visant à éliminer ce que l'on croyait être la source véritable de ses symptômes. Au lieu de cela, la cause s'est révélée être une sarcoïdose ne touchant que les voies aériennes principales, sans adénopathie intrathoracique, atélectasie, infiltrats du parenchyme pulmonaire ou signes de maladie extrapulmonaire. La patiente a rapidement répondu à des glucocorticoïdes par voie générale, auxquels a été ajoutée par la suite avec succès une corticothérapie par inhalation pour une toux persistante.
$E^{n}$ ndobronchial involvement in sarcoidosis can mimic asthma or malignancy (1-3). However, the simultaneous absence of pulmonary parenchymal infiltrates, mediastinal adenopathy or atelectasis at presentation is quite rare.

\section{CASE PRESENTATION}

A 32-year-old woman was to have excision of a benign goiter when the distal trachea appeared abnormal during fiberoptic intubation. While still under general anesthesia, the authors were called to evaluate her for the first time. A review of her chart revealed dyspnea on exertion and nonproductive cough for three months. Her primary care physician had noted wheezing on examination and prescribed albuterol as needed and triamcinolone acetonide inhaler two puffs $(100 \mu \mathrm{g} / \mathrm{puff})$ tid after making a clinical diagnosis of asthma. However, she continued to make emergency room visits. Her compliance with this regimen was unknown. On examination in the operating room, she had a $3 \mathrm{~cm}$ by $3 \mathrm{~cm}$ right-sided goiter and diffuse inspiratory wheezing, on the left side more than the right. She was a nursing student who had smoked one pack of cigarettes per day for 10 years but had quit three years earlier. She did not use illicit drugs, and occupational history was otherwise negative. Chest $\mathrm{x}$-ray (CXR) and computed tomography (CT) of the chest, completed within one week before admission, are shown in Figures $1 \mathrm{~A}$ and 1B, respectively.
Flexible bronchoscopy was performed, which revealed erythema and nodularity of the mucosa involving the trachea and extending to the main stem bronchi. The left main stem bronchus was severely narrowed (Figure 1C). The bronchoscope could not be advanced beyond the level of the left upper lobe orifice. Endobronchial biopsies were performed and surgery was cancelled.

She was transferred to the intensive care unit and was started on intravenous methylprednisolone $60 \mathrm{mg}$ every $6 \mathrm{~h}$ because of intense inflammation of the airways and a history of asthma. After four days she was extubated, and methylprednisolone was discontinued. Biopsies showed noncaseating granulomas without evidence of mycobacterial or fungal infection on tissue stains or bronchial wash stains and cultures. Results of fungal and connective tissue disease serologies were negative. A tuberculin skin test was nonreactive. She denied exposure to known causes of hypersensitivity pneumonitis, and did not travel to areas endemic for dimorphic fungi. Spirometry, tests of lung volumes and carbon monoxide diffusing capacity, and a flow volume loop (FVL) were performed one day after extubation. All of these results were normal, including both limbs of the FVL. The patient elected not to start oral glucocorticoids and was discharged home. Due to persistent cough, bronchoscopy was repeated two weeks later and showed a significant decrease in airway

Section of Pulmonary and Critical Care Medicine, Baylor College of Medicine, Houston, Texas, USA

Correspondence: Dr Elizabeth Guy, Section of Pulmonary and Critical Care Medicine, Ben Taub General Hospital, 1504 Taub Loop, Sixth Floor, Houston, Texas 77030, USA. Telephone 713-873-2468, fax 713-790-9576, e-mail guy@bcm.tmc.edu 


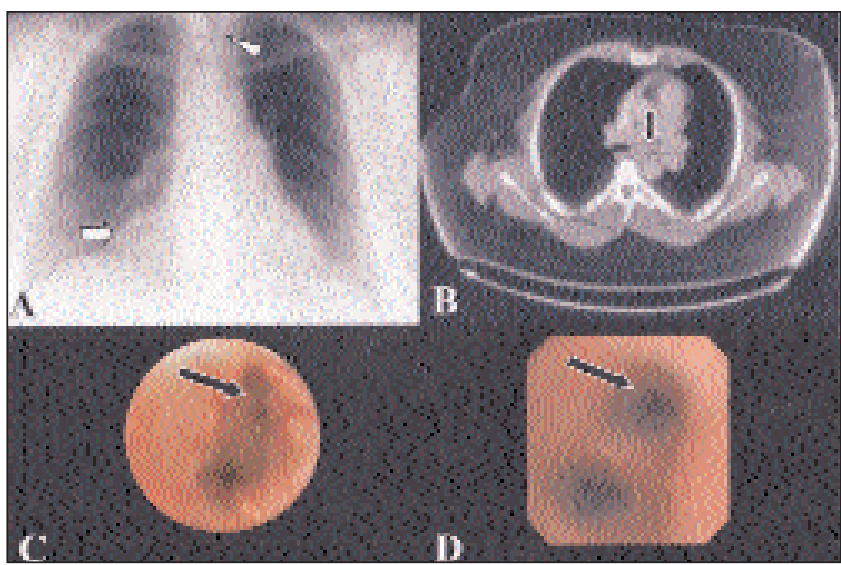

Figure 1) A Chest x-ray shows deviation of the trachea due to goiter (arrowhead) and a mediastinal lipoma (arrow) confirmed by computed tomography of the chest. B Computed tomography of the chest shows thickening of the wall of the left main stem bronchus. C, D Endoscopic view of the left main stem bronchus at the level of the left upper lobe orifice at presentation (bronchoscope is wedged - C) and three weeks later (D). Arrows indicate the left upper lobe orifice

narrowing (Figure 1D). The left bronchial tree was easily explored, but there was still intense erythema, mainly of the trachea and main stem bronchi. CXR and spirometry with a FVL showed no changes. This time, endobronchial biopsies only showed submucosal inflammation, and cultures were again negative. It was decided to treat the patient with fluticasone $440 \mu \mathrm{g}$ twice daily. After four weeks of therapy, her cough resolved. The patient was not followed up further until one year later, when she returned to the outpatient clinic with a persistent, nonproductive cough. She had discontinued fluticasone soon after her symptoms resolved and was not on any other therapy. CXR, spirometry, tests of lung volumes and carbon monoxide diffusing capacity, and a FVL were repeated without new findings. Bronchoscopy was again performed, and this time, it revealed minimal nodularity of the left main stem, right upper lobe and right middle lobe bronchi with mild diffuse erythema. Fluticasone was prescribed as previously, but she has not made any more clinic visits to date.

\section{DISCUSSION}

The first case of endobronchial involvement in sarcoidosis was reported in 1941 (4). Spirometry showed that obstruction was common ( $40 \%$ by current criteria) (5), while bronchoscopic evaluation showed a wide spectrum of involvement, including longitudinal stenosis $(1,5)$ and mass-like lesions $(2,3)$. Our patient had disease confined to the airway without intrathoracic adenopathy, atelectasis or parenchymal pulmonary infiltrates, and this was confirmed by CT scan of the chest. We found only two cases with similar presentations in which CT scan was performed. In the first case, "the hila appeared somewhat prominent" on CT of the chest, and extrapulmonary disease was also present on physical examination (6). In the second case, CT showed "small areas of atelectasis" (7). These findings were not present in our patient, but thickening of the left main stem bronchus was seen on CT of the chest (Figure 1B).
Endobronchial bronchoscopic biopsy in airway sarcoidosis often provides the characteristic but not diagnostic histological findings in up to $75 \%$ of cases, especially when the mucosa appears abnormal (8). Other etiologies of noncaseating granulomas were ruled out in this patient by a complete history for possible exposure to dusts, antigens and pathogens, as well as by serologies and repeated cultures of bronchial specimens. The patient's goiter was an unlikely cause for her respiratory symptoms, as evidenced by a normal FVL performed after improvement of symptoms. She had a needle aspiration three years earlier that was not compatible with sarcoidosis.

Although there seemed to be a temporal relation between the treatment and the patient's response, the treatment course was much shorter than recommended (9). Resolution of airway edema may explain this rapid response. Spontaneous resolution of sarcoidosis occurs in up to two-thirds of patients (10), but endobronchial involvement, on the other hand, is reported to convey a worse prognosis (11). Inhaled glucocorticoids may improve cough (12), and this patient was an appropriate candidate because CT scan did not reveal any infiltrates. The use of systemic glucocorticoids followed by inhaled glucocorticoids has been shown to be more effective than placebo in stage II pulmonary disease (13) and is somewhat similar to the treatment that our patient received.

Sarcoidosis can mimic asthma by different potential mechanisms. Symptoms such as cough and wheezing may be due to bronchostenosis, focal endobronchial lesions or extrinsic compression by lymph nodes, but airway hyper-reactivity may also play a role (14). The latter might have been present in our patient, as evidenced by persistent, nonproductive cough and intense erythema of the airway at presentation, though confirmation with methacholine challenge testing was not undertaken. A FVL can be helpful (6) but is not sensitive enough to exclude obstruction of the major airways (15).

\section{CONCLUSIONS}

Sarcoidosis should be included in the differential diagnosis of persistent asthma, even if a plain radiograph does not exhibit features of this disease and extrapulmonary clinical findings are absent. A CT scan of the chest may prove useful in prompting further investigation with bronchoscopy. More often than not, biopsy of abnormal appearing bronchial mucosa leads to the diagnosis.

ACKNOWLEDGEMENTS: Production of illustrations was funded by the section of Pulmonary and Critical Care Medicine, Baylor College of Medicine, Houston, Texas, USA.

\section{REFERENCES}

1. Olsson T, Bjornstad-Pettersen H, Stjernberg NL. Bronchostenosis due to sarcoidosis: A cause of atelectasis and airway obstruction simulating pulmonary neoplasm and chronic obstructive pulmonary disease. Chest 1979;75:663-6.

2. Corsello BF, Lohaus GH, Funahashi A. Endobronchial mass lesion due to sarcoidosis: Complete resolution with corticosteroids. Thorax 1983;38:157-8.

3. Abramowicz MJ, Ninane V, Depierreux M, de Francquen $P$, Yernault JC. Tumor-like presentation of pulmonary sarcoidosis. Eur Respir J 1992;5:1286-7.

4. Benedict E, Castleman B. Sarcoidosis with bronchial involvement. N Engl J Med 1941;224:186-9. 
5. Harrison BD, Shaylor JM, Stokes TC, Wilkes AR. Airflow limitation in sarcoidosis: A study of pulmonary function in 107 patients with newly diagnosed disease. Respir Med 1991;85:59-64.

6. Miller A, Brown L, Teirstein A. Stenosis of main bronchi mimicking fixed upper airway obstruction in sarcoidosis. Chest 1985;88:244-8.

7. Murray ME, Stokes TC. Endobronchial sarcoidosis presenting as severe upper airways narrowing with normal chest radiograph. Respir Med 1991;85:425-6.

8. Shorr AF, Torrington KG, Hnatiuk OW. Endobronchial biopsy for sarcoidosis: A prospective study. Chest 2001;120:109-14.

9. American Thoracic Society. Statement on sarcoidosis. Am J Respir Crit Care Med 1999;160:736-55.

10. Lynch JP 3rd, Kazerooni EA, Gay SE. Pulmonary sarcoidosis. Clin Chest Med 1997;18:755-85.

11. Bjermer L, Thunell M, Rosenhall L, Stjernberg N. Endobronchial biopsy positive sarcoidosis: Relation to bronchoalveolar lavage and course of disease. Respir Med 1991;85:229-34.

12. Paramothayan NS, Jones PW. Glucocorticoids for pulmonary sarcoidosis (Cochrane Review). In: The Cochrane Library, Issue 4. Oxford: Update Software, 2001.

13. Pietinalho A, Tukiainen P, Haahtela T, Persson T, Selroos O. Oral prednisolone followed by inhaled budesonide in newly diagnosed pulmonary sarcoidosis: A double-blind, placebo-controlled multicenter study. Finnish Pulmonary Sarcoidosis Study Group. Chest 1999;116:424-31

14. Bechtel JJ, Starr T 3rd, Dantzker DR, Bower JS. Airway hyperreactivity in patients with sarcoidosis. Am Rev Respir Dis 1981;124:759-61.

15. Miller RD, Hyatt RE. Obstructing lesions of the larynx and trachea: Clinical and physiologic characteristics. Mayo Clin Proc $1969 ; 44: 145-61$ 


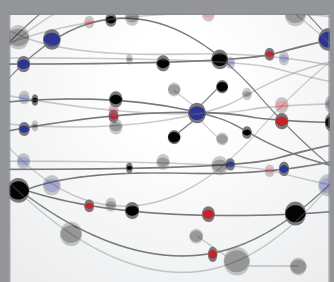

The Scientific World Journal
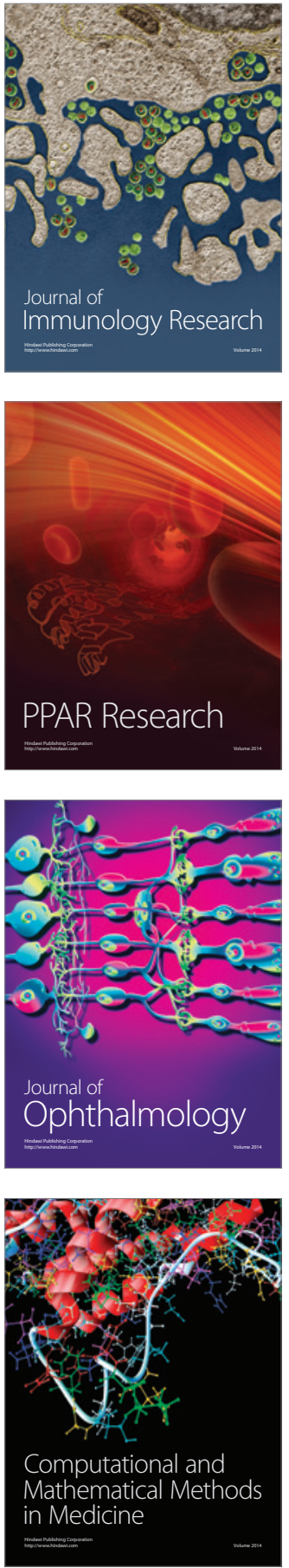

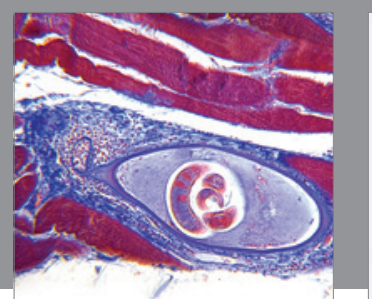

Gastroenterology Research and Practice

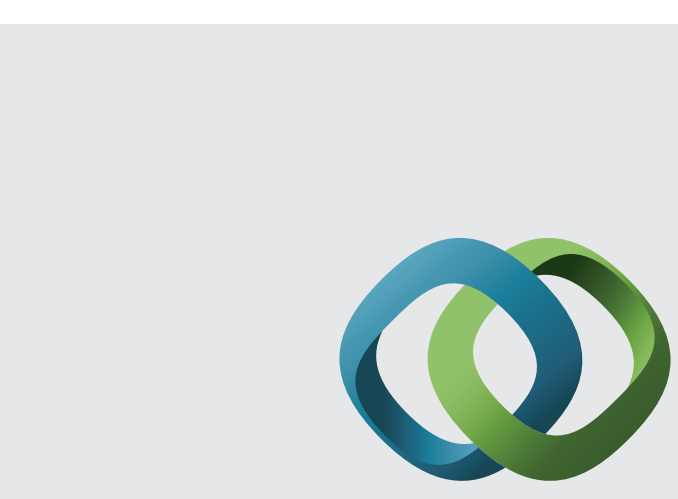

\section{Hindawi}

Submit your manuscripts at

http://www.hindawi.com
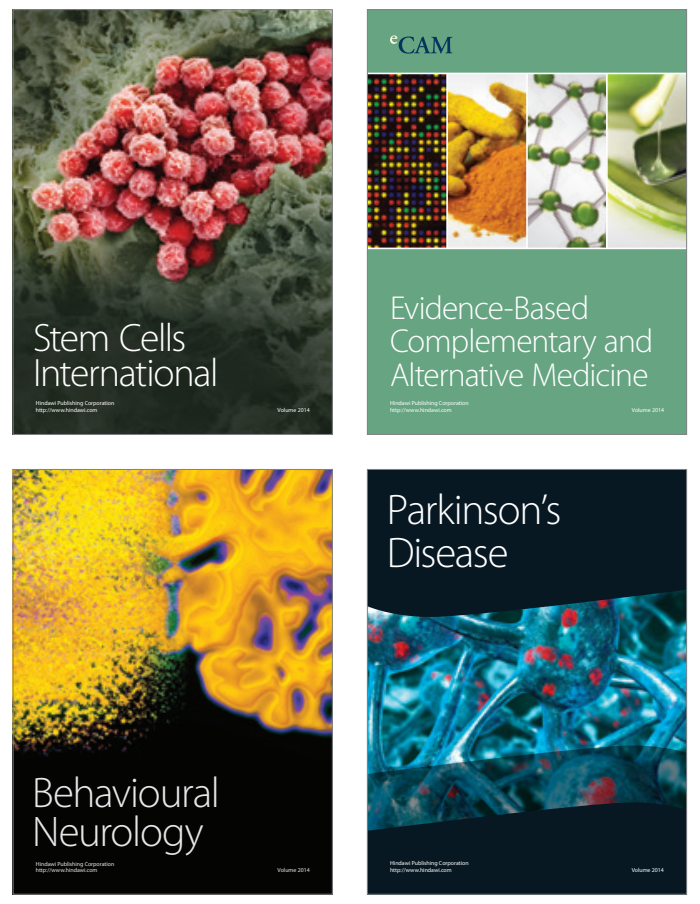
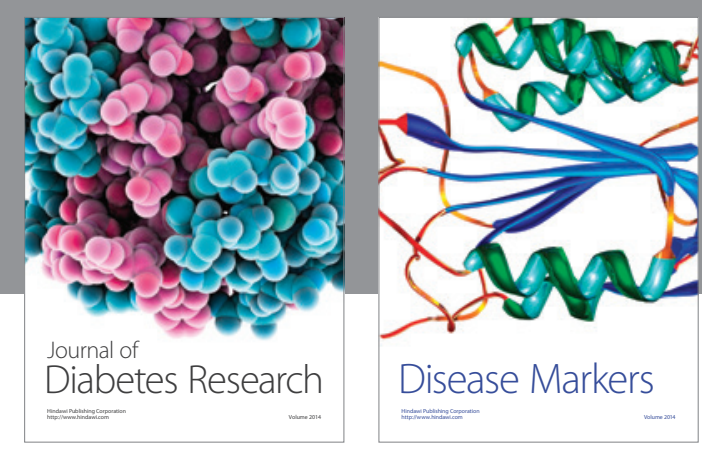

Disease Markers
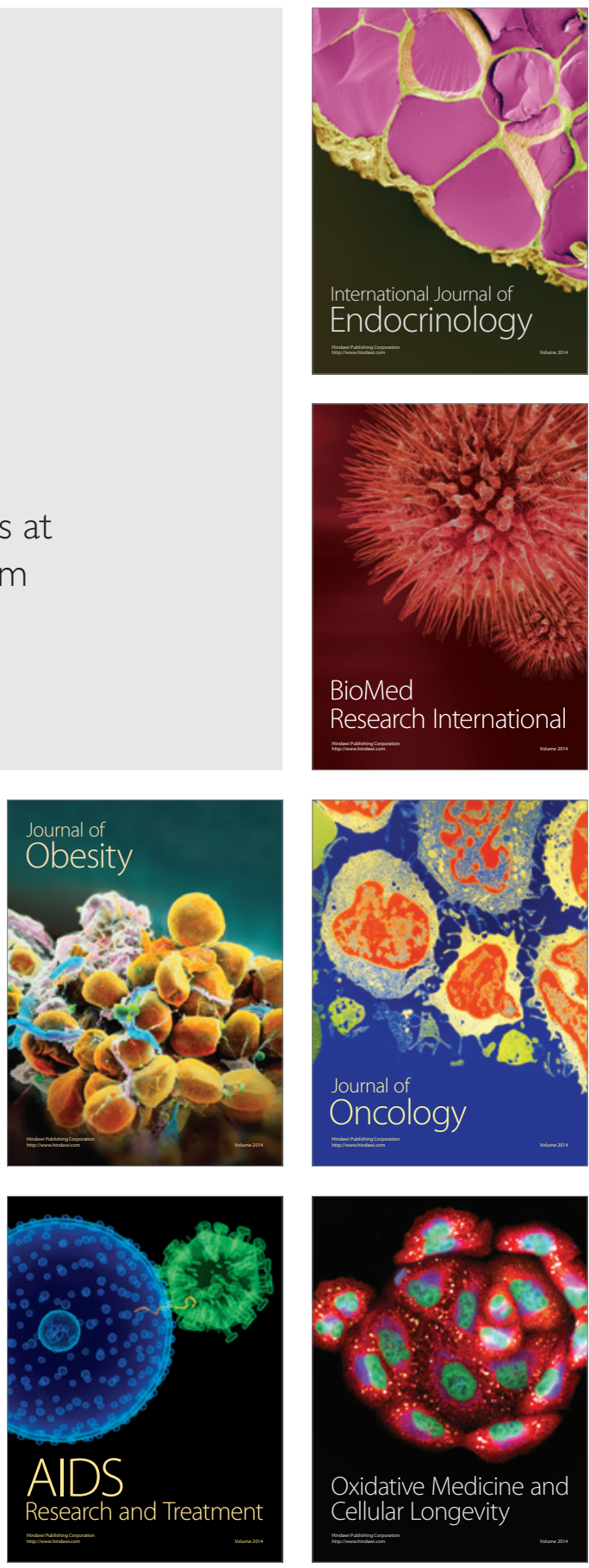